\title{
Structure Properties of Knits from Natural Yarns and their Combination with Elastane and Polyamide Threads
}

\author{
Jovita ABRAMAVIČIŪTE் * , Daiva MIKUČIONIENĖ, Ričardas ČIUKAS \\ Department of Textile Technology, Kaunas University of Technology, Studentu 56, LT-51424 Kaunas, Lithuania \\ Received 15 October 2010; accepted 10 February 2011
}

\begin{abstract}
This paper presents a study on structure of knits for socks manufactured using the yarns of new kind of fibres as soybean and bamboo. Structure properties of plain pure knits and plated knits with textured polyamide and elastane wrapped with textured polyamide threads are investigated. Pure knits have looser structure, higher porosity, low thickness and area density. Textured polyamide or elastane threads change the structure of plated knits, as constructions of such knits are thicker, heavier and tighter. Higher course and wale density have knits plated with elastane thread. Verification of correlation between tightness factor of samples from pure yarns, their combination with elastane and textured polyamide threads and area density, loop length and thickness was performed.

Keywords: plated knits, linear density, area density, loop length, tightness factor.
\end{abstract}

\section{INTRODUCTION}

Knitted goods of all kinds are generally popular because of their flexibility, ability to adapt as well as stretch them to a particular shape when worn, and because of their general comfortable wear. The dimensional stability of knitted structures from mostly conventional yarns together with other physical properties has been one of the most extensively discussed subjects in research $[1-16]$.

Today, the knitting industry mostly uses elastane combined with cotton, especially for sportswear, foundation garments, intimate apparels, etc., due to outstanding features of spandex such as higher elastic recovery, good shape retention properties, soft and smooth handle, abrasion resistance, resistance to pilling, resistance to most chemicals, resistance to normal apparel exposure to sunlight and lower moisture regain [3].

With the growing demand for more comfortable, healthier and environmentally friendly products, efforts in research and development activities in the textile industry have focused on the utilization of renewable and biodegradable resources. In this respect, a new kind of soybean, bamboo, seacells and their blends with traditional fibres as cotton, flax was analysed [4]. These fibres have good influence on human. Bamboo fibre is natural antibacterial and biodegradable, has high moisture absorption capacity, softness, brightness as well as UV protective properties [4]. Soy fibre also is natural antibacterial, has good mechanical and physical performances, soft and smooth handle, good moisture absorption and permeability [5]. Seacell fibre is saturated with various minerals, microelements and vitamins. While wearing this fibre, skin feels crème-effect. Seacell is protecting the skin, has antiphlogistic, antiallergic properties [6].

Y. Beceren et al investigated dimensional and physical properties of plain jersey fabrics made from viscose

\footnotetext{
* Corresponding author. Tel.: +370-689-50814; fax.: +370-37-353989.

E-mail address: jovita.abramaviciute@stud.ktu.lt (J. Abramavičiūtẻ)
}

sirospun and carded ring yarns. They noticed that stitch density decreased and the weight increased as the stitch length increased, the twist of yarn had an influence on fabric properties [1].

Many researches mention that geometrical and dimensional parameters such as a loop shape factor (directly affecting fiber orientation), loop length and fabric tightness factor (directly influencing fiber volume fraction) are very important parameters. The number of courses per $\mathrm{cm}$ and number of wales per $\mathrm{cm}$ have linear relations with the inverse of the loop length; the regression analysis has shown that correlation of courses per $\mathrm{cm}$ with loop length is more significant. The yarn linear density is a predominant factor which affects the thickness of knitted fabric [7-10]. Some authors investigated knits with elastane thread $[1,11]$. They noted that cotton knitted yarns with elastomeric component increase the tightness of single jersey knits and result in more favourable dimensional stability than cotton knits without elastane. Higher stitch density, weight, thickness of cotton/spandex structures than cotton single jersey structures, under the same machine set stitch lengths $[3,11]$.

$\mathrm{S}$. Tezel et al investigated the effects of elastane brands, the tightness factor of the base and elastane yarn on the dimensional and physical properties of cotton/elastane single jersey fabrics. They found that all these factors significant influence on weight, loop length, course and wale densities and thickness of cotton/elastane single jersey fabrics [12].

There is limited literature on properties of knits from new generation fibres with elastane thread despite the fact that elastane is mostly used in the knitting industry. The main goal of this study was to establish influence of fibre composition on structural properties of knits manufactured from cotton, bamboo, soybean yarns and its combination with textured polyamide and elastane threads.

In this paper, structural parameters such as wale and course spacing, densities, thickness, area density, tightness factor, area density, loop lenght of knits from cotton, bamboo and soy yarns are investigated. 
Table 1. Results of structural and calculated parameters

\begin{tabular}{|c|l|c|c|c|c|c|c|}
\hline \multicolumn{1}{|c|}{ Indication of knitted sample variant } & $\begin{array}{c}\text { Course } \\
\text { density, } \\
\mathrm{cm}^{-1}\end{array}$ & $\begin{array}{c}\text { Wale } \\
\text { density, } \\
\mathrm{cm}^{-1}\end{array}$ & $\begin{array}{c}\text { Area } \\
\text { density } \\
M, \mathrm{~g} / \mathrm{m}^{2}\end{array}$ & $\begin{array}{c}\text { Thickness } \\
b, \text { mm }\end{array}$ & $\begin{array}{c}\text { Loop } \\
\text { length } l, \\
\mathrm{~mm}\end{array}$ & $\begin{array}{c}\text { Tightness } \\
\text { factor, } T F\end{array}$ \\
\hline CE & Cotton 14 tex + Elastane 10 tex & 17.0 & 10.0 & 236 & 0.71 & 5.71 & 8.63 \\
\hline BE & Bamboo 14 tex + Elastane 10 tex & 17.0 & 10.0 & 287 & 0.89 & 7.03 & 6.96 \\
\hline SE & Soy 14 tex + Elastane 10 tex & 17.0 & 10.0 & 280 & 0.92 & 6.86 & 7.14 \\
\hline CC & Cotton 14 tex + Cotton 14 tex & 7.4 & 6.3 & 88 & 0.39 & 6.60 & 8.10 \\
\hline BB & Bamboo 14 tex + Bamboo 14 tex & 7.4 & 6.2 & 91 & 0.38 & 7.08 & 7.47 \\
\hline SS & Soy 14 tex + Soy 14 tex & 10.0 & 8.3 & 192 & 0.81 & 6.74 & 8.68 \\
\hline CPA & Cotton 14 tex + PA 20 & 10.0 & 8.3 & 201 & 0.77 & 7.12 & 8.19 \\
\hline BPA & Bamboo 14 tex + PA 20 tex & 9.8 & 8.3 & 188 & 0.75 & 6.80 & 8.58 \\
\hline SPA & Soy 14 tex + PA 20 tex & 13.0 & 10.0 & 293 & 0.79 & 5.84 & 10.64 \\
\hline CCE & Cotton 14 tex + Cotton 14 tex + Elastane 10 tex & 15.0 & 10.0 & 321 & 0.92 & 5.63 & 10.95 \\
\hline BBE & Bamboo 14 tex + Bamboo 14 tex + Elastane 10 tex & 16.0 & 10.0 & 338 & 0.94 & 5.56 & 11.09 \\
\hline SSE & Soy 14 tex + Soy 14 tex + Elastane 10 tex & 7.8 & 7.7 & 156 & 0.55 & 6.48 & 10.12 \\
\hline CCC & Cotton 14 tex + Cotton 14 tex + Cotton 14 tex & 7.2 & 7.0 & 164 & 0.52 & 7.54 & 8.60 \\
\hline BBB & Bamboo 14 tex + Bamboo 14 tex + Bamboo 14 tex & 7.2 & 94 & 0.39 & 7.32 & 7.23 \\
\hline SSS & Soy 14 tex + Soy 14 tex + Soy14 tex & 7.4 & 7.1 & 152 & 0.54 & 6.99 & 9.28 \\
\hline CCPA & Cotton 14 tex+ Cotton 14 tex + PA 20 tex & 10.0 & 8.2 & 248 & 0.88 & 6.22 & 11.20 \\
\hline BBPA & Bamboo 14 tex + Bamboo 14 tex + PA 20 tex & 10.0 & 8.2 & 269 & 0.90 & 6.83 & 10.14 \\
\hline SSPA & Soy 14 tex + Soy 14 tex + PA 20 tex & 9.4 & 8.0 & 244 & 0.89 & 6.76 & 10.25 \\
\hline
\end{tabular}

Note: the relative error of all measurements is less than $5 \%$.

\section{EXPERIMENTAL}

Methods and materials. Socks commonly are knitted in plain pattern from cotton yarns plated with textured polyamide (PA) or elastane wrapped with textured PA threads.

Two sets of experimental samples knitted in plain jersey and plain plating patterns were used. Plain knits were knitted from pure cotton (C), bamboo (B), and soybean (S) yarns using one (14 tex linear density), two $(14$ tex $\times 2)$, and three $(14$ tex $\times 3)$ yarns. One part of plated knits was knitted from 14 tex $\times 2$ and 14 tex $\times 3 \mathrm{C}$, B, and S yarns combined with 10 tex textured PA thread with wrapped Lycra. Other part of plated knits was knitted from 14 tex $\times 2$ and 14 tex $\times 3 \mathrm{C}, \mathrm{B}$, and $\mathrm{S}$ yarns combined with 20 tex textured PA threads. Combination from two or three yarns with polyamide and elastane threads allow get knits with the same linear density but in different fibres, and from the same fibre but with different linear density. The knits were knitted on a 14 gauge, 168 needles, and 33/4" diameter Matec-Techno New socks knitting machine. Knitted samples were kept in a steam box for 20 minutes. Before investigation, knitted fabrics were conditioned in standard conditions: relative humidity $(65 \pm 2) \%$ and temperature $(20 \pm 2){ }^{\circ} \mathrm{C}$. The variants of knits are presented in Table 1.

The course and wale density of samples were counted according standard in longitudinal and transverse directions at $10 \mathrm{~cm}$ distance and evaluated per $\mathrm{cm}$ [13]. The area density of samples was obtained from measurements of $10 \mathrm{~cm} \times 10 \mathrm{~cm}$ samples, and is reported in $\mathrm{g} / \mathrm{m}^{2}[14]$. The yarns linear density was estimated before knitting.

The stitch length of plain knits for sock was determined from area density expression [15]:

$$
l=\frac{M \cdot A \cdot B}{T},
$$

where: $l$ is the loop length of knitted samples in $\mathrm{mm} ; M$ is the area density of knitted sample in $\mathrm{g} / \mathrm{m}^{2} ; A$ is the wale spacing of knitted sample in $\mathrm{mm} ; B$ is the course spacing of knitted sample in $\mathrm{mm} ; T$ is the linear density of yarns in tex.

It is known that majority of knits features depends on loop length and yarn linear density. The tightness of knits was characterized by the tightness factor $(T F)$. It is known that $T F$ is a ratio of the area covered by the yarns in one loop to the area occupied by that loop [15]. It is also an indication of the relative looseness or tightness of the plain knitted weft structure. For determination of $T F$ the formula $[15,16]$ was used:

$$
T F=\frac{\sqrt{T}}{l} \text {. }
$$

The thickness of knitted samples was measured in accordance with ISO 5084:1996 standard [17].

\section{RESULTS AND DISCUSSION}

Six groups of knits with the same linear density of yarns in this research were analysed. First group of knits is (SE, CE, BE) from 24 tex yarns, second (SS, CC, BB) from 28 tex, third (SPA, CPA, BPA) - 34 tex, fourth (SSE, CCE, BBE) - 38 tex, fifth (SSS, CCC, BBB) - 42 tex, sixth (SSPA, CCPA, BBPA) - 48 tex.

Comparing average thickness of all knits group, we can see that there are differences in these groups: $1^{\text {st }}-0.84$ $\mathrm{mm}, 2^{\text {nd }}-0.39 \mathrm{~mm}, 3^{\text {rd }}-0.78 \mathrm{~mm}, 4^{\text {th }}-0.88 \mathrm{~mm}$, $5^{\text {th }}-0.54 \mathrm{~mm}, 6^{\text {th }}-0.88 \mathrm{~mm}$. Highest thickness have knits plated with elastane thread. The thickness of CPA $(0.81 \mathrm{~mm})$ differs from thickness of SPA $(0.75 \mathrm{~mm})$ and 
BPA $(0.77 \mathrm{~mm})$. The calculated relative error values of thickness didn't exceed $5 \%$.

The course and wale spacing are most important factors, as they are directly related to course and wale densities, which represent the changes of stitch shape using various plated yarns [2,3]. From Table 1 it could be seen that course and wale densities of knits scatter very different comparing pure knits, knits plated with textured PA or elastane threads. Higher course and wale densities have knits plated with elastane thread under the same machine set stitch lengths due to yarn relaxation; it brings lower porosity of knit. Course density of these knits is higher in $56 \%$, wale density is higher in $38 \%$ than of pure cotton, bamboo, and soybean knits. Course and wale densities of knits plated with elastane is $41 \%$ and $17 \%$ respectively higher than knits plated with PA thread for all knits variants, so knits with elastane are tighter. According to $[3,11,12,18]$, due to elastic recovery property of elastane thread, stitch length in knit reduces. We found that loop length reduce about $16 \%, 1 \%, 7 \%$ respectively of $\mathrm{C}, \mathrm{B}, \mathrm{S}$ knits plated with elastane (when two yarns for loop were used) and $11 \%, 34 \%, 26 \%$ (when three yarns for loop were used) comparing with pure $\mathrm{C}, \mathrm{B}, \mathrm{S}$ knits respectively. There is tendency that loop length becomes shorter while more yarns have knit loop. It is obviously in variant when comparing two and three yarns for loop. Loop length decrease about $0 \%, 4 \%$ and $13 \%$ respectively of pure $C$, B, S knits, knits plated with PA and knits plated with elastane. Therefore, ultimately course and wale spacing reduce, because reduce the course and wale heights. Pure knits are looser and porosity is higher. Such knits are suitable for warm climate, because human will feel comfort and cool wearing such socks. Variation tendency of course and wale density of knits manufactured from three yarns are the same. Density of these knits decrease because for knit three yarns were used, knitted fabric becomes thicker, porosity decrease because spacing between loop decreases as well $[7,11]$.

From Table 1 we may see that knits plated with elastane distinguish with higher area density. The same tendency was found by other researchers $[9,11,12]$. We found that area density higher about $66 \%$ than pure C, B, $\mathrm{S}$ knits and comparing knits plated with PA, area density higher about $50 \%$ than pure $\mathrm{C}, \mathrm{B}, \mathrm{S}$ knits. It could be explained that loop length becomes shorter, density of knit increase so knit are more tighten and heavier. The calculated relative error values of area density didn't exceed $3 \%$.

To describe the dependence of course and wale spacing on thickness, polynomial equation was used. In Fig. 1 dependence of course spacing on thickness of knits from C, B, and S yarns is presented. From this figure we could find out maximum area, according which we may get knits with optimal parameters and which will distinguish with the best features. It would be: thickness about $0.7 \mathrm{~mm}-0.8 \mathrm{~mm}$ for knits from bamboo and soybean yarns of all knits variants and $0.8 \mathrm{~mm}-0.9 \mathrm{~mm}$ for knits from cotton yarns. The results show that course spacing has greater influence on thickness than wale spacing (Fig. 2). As we can see, the maximum there is only for knits from $\mathrm{C}$ yarns, and these results show that with increasing of wale spacing the thickness of knits from B and $\mathrm{S}$ yarns decreases. The similar results were observed by $[7,12,18]$.

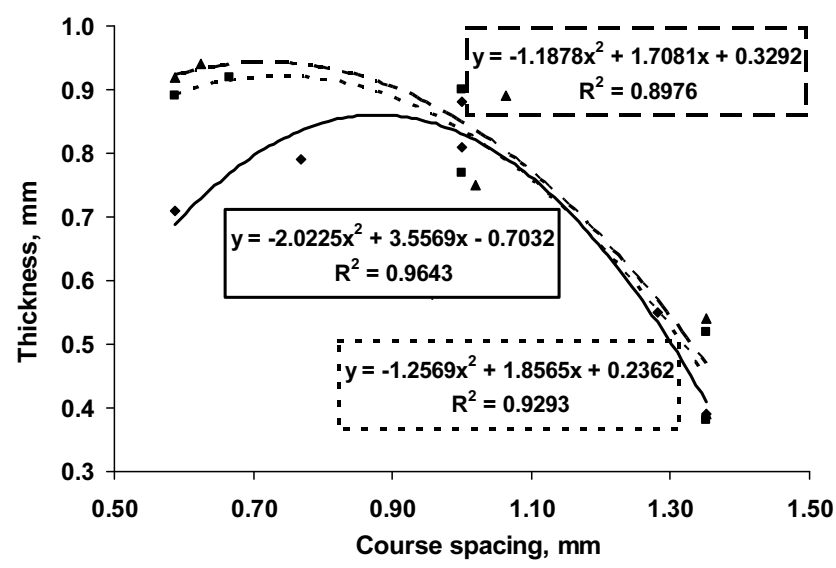

Fig. 1. Course spacing versus thickness of all cotton ( $\bullet$ ), bamboo $(\boldsymbol{\square})$, soy $(\boldsymbol{\Delta})$ plain and plated knits variants

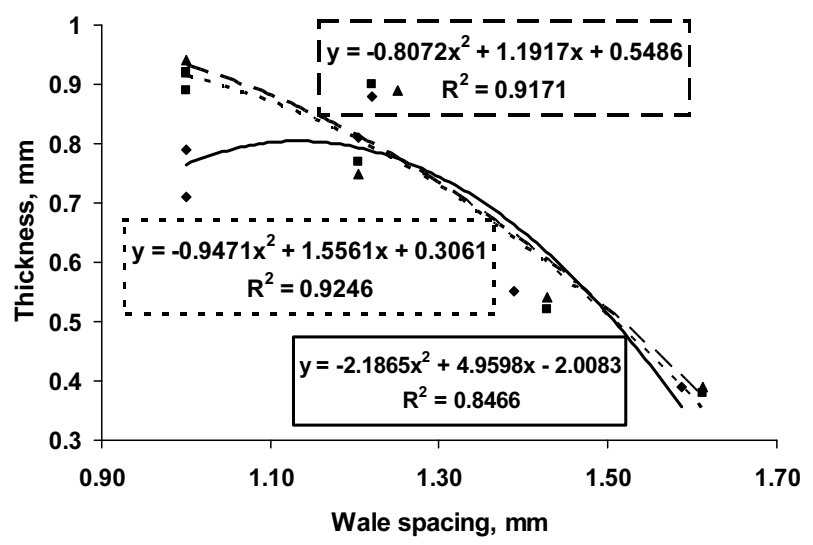

Fig. 2. Wale spacing versus thickness of all cotton ( $\bullet$, bamboo $(\boldsymbol{\square})$, soy $(\boldsymbol{\Delta})$ plain and plated knits variants

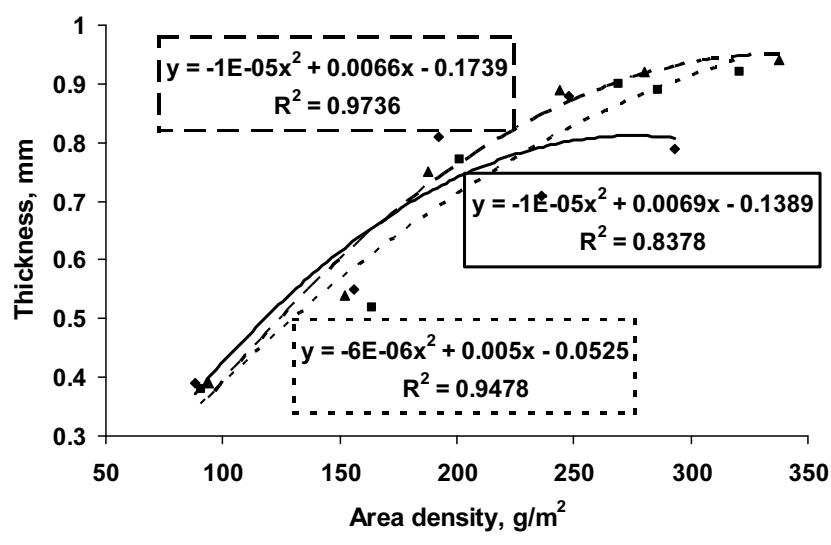

Fig. 3. Area density versus thickness of all cotton ( ), bamboo $(\boldsymbol{\square})$, soy $(\boldsymbol{\Delta})$ plain and plated knits variants

Dependences of area density and thickness of knits from $\mathrm{C}, \mathrm{B}$, and $\mathrm{S}$ yarns are presented in Fig. 3. Optimal area of these curvatures are: for cotton area density $208 \mathrm{~g} / \mathrm{m}^{2}$ and thickness $0.73 \mathrm{~mm}$, for bamboo area density $191 \mathrm{~g} / \mathrm{m}^{2}$ and thickness $0.72 \mathrm{~mm}$, for soybean area density $218 \mathrm{~g} / \mathrm{m}^{2}$ and thickness $0.81 \mathrm{~mm}$. From Fig. 3 we may confirm proposition mentioned before that increasing of area density, thickness increases as well, like it was demonstrated in $[7,11,12]$. 
Verification of correlation between tightness factor of samples from pure yarns, their combination with elastane and textured polyamide threads and area density, loop length and thickness was performed. Correlation coefficient for knits from pure yarns and plated knits with textured polyamide and elastane threads was calculated. Tightness factor have strong relation with area density, but only of $2^{\text {nd }}(r=0.90), 5^{\text {th }}(r=0.96)$ groups. A little bit lower relation was with thickness $b$ of $2^{\text {nd }}(r=0.85), 5^{\text {th }}$ $(r=0.80)$ and $6^{\text {th }}(r=0.85)$ groups. We may to do assumption that it is because of similar thickness of cotton, bamboo and soy knits in these groups. There is strong relation between area density and thickness of knits from $1^{\text {st }}(r=0.94), 2^{\text {nd }}(r=0.98), 5^{\text {th }}(r=0.97)$ and $6^{\text {th }}(r=0.95)$ groups. These relations confirm function of Fig. 3 and moreover support that strongest relation is for before mentioned groups. Furthermore there is correlation between loop length and area density $(r=0.82)$, loop length and thickness $(r=0.89)$ are only of $4^{\text {th }}$ knit group, it is obvious that area density, loop length and thickness are highest of this group with elastane thread. Coefficient of other groups not exceed value $r=0.80$.

\section{CONCLUSIONS}

Comparing pure knits from cotton, bamboo and soybean yarns it may be seen, that the knits from cotton are characterized by lower area density and loop length but have higher tightness factor than knits from bamboo and soybean yarns. There is a tendency that the loop knitted from more yarns is shorter.

Textured threads increase thickness and area density of knits. Higher course and wale densities have knits plated with elastane thread under the same machine set stitch lengths (due to yarn relaxation) than knits from pure yarns. Loop length becomes shorter, density of knit increases so knit is more tighten and heavier. Thickness and area density of the knits with elastane is higher about $50 \%$ than pure knits.

Comparing knits from two and three cotton, bamboo, or soybean yarns, course and wale densities remain almost unchanged.

There is stronger relation between the course spacing and thickness than between the wale spacing and thickness because its variation is very small in all groups.

There are differences comparing knits from pure yarns and plated knits, for a cold season most comfortable socks would be knitted from composition with polyamide and elastane thread as these are characterized by higher area density, course and wale densities, knits are thicker and tighter and human would feel warm wearing such socks. Socks from pure yarns should be used for a warm season as this is characterized by looser structure, low densities.

\section{REFERENCES}

1. Beceren, Y., Candan, C., Cimilli, S., Ulger, K. Properties of Plain Knits from Siro-Spun Viscose/Spandex Yarns Fibres \& Textiles in Eastern Europe 18 (1) 2008: pp. $41-46$.
2. Mikučionienė, D., Laureckienè, G. The Influence of Drying Conditions on Dimensional Stability of Cotton Weft Knitted Fabrics Materials Science (Medžiagotyra) 15 (1) 2009: pp. 64-68.

3. Herath, C. N., Kang, B. Dimensional Stability of Core Spun Cotton/Spandex Single Jersey Fabrics under Relaxation Textile Research Journal 78 (3) 2008: pp. 209-216.

4. Erdumlu, N., Ozipek, O. Investigation of Regenerated Bamboo Fibre and Yarn Characteristics Fibres \& Textiles in Eastern Europe 16 (4) 2008: pp. 43-47.

5. You, L. Y. The Soybean Protein Fibre - A Healthy \& Comfortable Fibre for the $21^{\text {st }}$ Century Fibres \& Textiles in Eastern Europe 12 (2) 2004: pp. 8-9.

6. www.ecoyarns.com.au/index.php?main page=product info \&products_id $=1038$, viewed:2009 0511.

7. Wang, Q. M., Hu, H. Geometrical and Dimensional Properties of Plain Knitted Fabrics Made from Glass Fiber Yarns for Composite Reinforcement Journal of Industrial Textiles 37 (2) 2007: pp. 139-148.

8. Rudd, C. D., Owen, M. J., Middleton, V. Mechanical Properties of Weft Knit Glass Fibre/Polyester Laminates Composites Science and Technology 39 (3) 1990: pp. $261-277$.

9. Knapton, J. J. F., Ahrens, F. J., Ingenthton, W. W., Fong, W. The Dimensional Properties of Knitted Wool Fabrics. Part I: The Plain-Knitted Structure Journal of Textile Institute 38 (10) 1968: pp. 999-1012.

10. Munden, D. L. The Geometry and Dimensional Properties of Jersey Knit Fabrics Journal of Textile Institute 50 (6) 1959: pp. $448-471$.

11. Marmarali, A. B. Dimensional and Physical Properties of Cotton/Spandex Single Jersey Fabrics Textile Research Journal 73 (12) 2003: pp. 11-14.

12. Tezel, S., Kavusturan, Y. Experimental Investigation of Effects of Spandex Brand and Tightness Factor on Dimensional and Physical Properties of Cotton/Spandex Single Jersey Fabrics Textile Research Journal 78 (11) 2008: pp. 966-976.

13. Textiles - Knitted Fabrics - Determination of Number of Stitches Per Unit Length and Unit Area. LST EN 14971:2006.

14. Textiles - Fabrics - Determination of Mass Per Unit Area Using Small Samples. LST EN 12127:1999.

15. Čiukas, R., Sadauskas, D. Theoretical Determination of Area Density and Tightness Factor for Weft knitted Fabrics International Textile, Clothing and Design Conference. Proceedings. Dubrovnik, Croatia, 2004: pp. 669-674.

16. Čiukas, R., Tvarijonavičienė, B., Mikučionienė, D. Estimation of Linear Density of Fancy Ribbon-Type Yarns and Structure Indices of Fabrics Knitted from Them Fibres \& Textiles in Eastern Europe 14 (4) 2006: pp. 41-43.

17. Textiles - Determination of Thickness of Textiles and Textile Products. ISO 5084:1996.

18. Gokarneshan, N., Thangamani, K. An Investigation into the Properties of Cotton/spandex and Polyester/spandex Knitted Fabrics The Journal of the Textile Institute 101 (2) 2010: pp. $182-186$.

Presented at the National Conference "Materials Engineering '2010" (Kaunas, Lithuania, November 19, 2010) 